ISMAEL MATA

Profesor en el posgrado de Derecho administrativo en las Universidades de Buenos Aires, Austral y Rosario, y en la Escuela del Cuerpo de Abogados del Estado de la Procuración del Tesoro de la Nación matayaso@ciudad.com.ar ORCID ID: https://orcid.org/0000-000 |-7|85-689|

Recibido: 12/10/2021 - Aceptado: I I/I I/2021

Para citar este artículo / To reference this article / Para citar este artigo Mata, I. (202I). Pandemia, Estado y empleo público. Revista de Derecho, 20(40), 9 | - I I2. https://doi.org/I 0.47274/DERUM/40.5

\title{
Pandemia, Estado y empleo público ${ }^{1}$
}

Palabras clave: Derecho Público, pandemia, Estado. 


\section{Pandemic, State and public employment}

Keywords: Public law, pandemic, state.

\section{Pandemia, o estado e emprego público}

Palavras-chave: Direito público, pandemia, Estado. 


\section{Estado Servicial y buena administración}

En el marco integral de un Estado al servicio de sus habitantes resultan indispensables el reconocimiento y la respuesta eficaz exigida por el derecho humanoa una buena administración, que como enseña Rodriguez Arana (2013), traen consigo

un replanteamiento del derecho administrativo en su conjunto. Ahora, desde la centralidad del ciudadano y desde su participación activa en la conformación de los intereses generales, el derecho administrativo y sus principales categorías deben ser nuevamente formulados puesto que ahora la relevancia de los derechos fundamentales de la persona sugiere nuevas formas de comprender el sistema del derecho administrativo (pp. 23-56).

En Argentina, por su parte, el modelo de "Estado Servicial" quedó consolidado con la reforma constitucional del año 1994, que introdujo el reconocimiento y protección de los derechos de consumidores y usuarios de bienes y servicios, y los principios de "calidad y eficiencia de los servicios públicos" (art. 42), que se articulan con los valores constitucionales originarios, de "bienestar general", "prosperidad del país" y "adelanto y bienestar de todas las provincias", y se suman a los incorporados por la reforma indicada, que son "desarrollo humano y progreso económico con participación social", “crecimiento armónico de la Nación", "bien general del Estado" y "grado equivalente de desarrollo, calidad de vida e igualdad de oportunidades en todo el territorio nacional" (estos dos últimos como inherentes a la política tributaria). En definitiva, como resultado de ese plexo articulado, según mi criterio, se produce el efecto expansivo de los principios de "calidad" y "eficiencia", tornándose exigibles paratodas las funciones y actividades del Estado, con el efecto sobre la Administración, dehacerla pasar de un modelo "burocrático", a otro dedicado al servicio efectivo de la gente, con el deber de desarrollar una buena gestión administrativa.

Con relación al modelo llamado "burocrático" esa denominación no tiene un sentido descalificante, sino que se refiere a una serie de rasgos culturales que en la actualidad resultan incompatibles con el Estado servicial, en particular, porque actúa básicamente con la mirada dirigida sobre sí mismo, circunstancia que en el mejor de los casos logra eficiencia, pero difícilmente la calidad exigida por una gestión servicial eficaz.

Resulta de utilidad la comparación entre ambos modelos, en particular, si debe examinarse el papel que les toca desempeñar a los agentes públicos en la nueva organización del Estado impactada por el fenómeno inesperado de la pandemia.

Por lo tanto, en primer lugar, corresponde destacar que el perfil del modelo burocrático ha sido condicionado por un entorno estatal, particularmente en Latinoamérica, en el cual puede advertirse la subordinación de la gestión administrativa a los cambios del ciclo político, con avances, retrocesos y aún de acciones propias del perjudicial "sistema de los despojos". A tales datos, puede añadirse la ausencia de planes y políticas públicas y sostenidas en el tiempo, sin olvidar un componente cultural de la atmósfera pública que es la "magia de las palabras", o sea, la creencia consistente en que los discursos, las declaraciones y la creación de nuevas normas tienen, por sí solos, un efecto transformador sobre la realidad, con el inevitable descuido por las acciones eficaces. 
En función de ese marco del sector público, el paradigma burocrático exhibe los rasgos siguientes:

- el cuidado por las competencias asignadas;

- el acento puesto sobre el cumplimiento de las reglas y las responsabilidades enlos casos de incumplimientos;

- tendencia a la abstinencia de resolver en los casos de problemas complejos;

- propensión a las respuestas negativas hacia los administrados;

- acciones ceñidas al costo y la cantidad de los insumos;

- desinterés por las acciones dirigidas a lo externo de la organización (despreocupación por la eficacia);

- la actividad asentada en documentos escritos.

Por su lado, una Administración Servicial debiera apuntar a los objetivossiguientes:

- procurar la adopción de planes y políticas públicas sostenidos en el tiempo;

- la obtención de resultados eficaces;

- la atención efectiva de las necesidades de la gente;

- la producción de valor neto del costo;

- motivar la participación de los administrados;

- la capacitación permanente de su personal;

- la aplicación de estándares de calidad en la gestión;

- regular y controlar no sólo con la aplicación de sanciones, sino también mediante la creación de incentivos, con el propósito de obtener conductas acordes con las políticas públicas.

La instalación de una Administración Servicial requiere la posibilidad de introducir cambios en la identidad de su organización, es decir, su cultura, constituida por un conjunto de reglas formales e informales que modelan los comportamientos de las personas que la integran; de ahí la enorme importancia que tienen las políticas que se siguen con los agentes públicos, en especial, respecto de su participación y capacitación.

En el mundo actual y, más aún, con el impacto de la pandemia, las organizaciones, sean públicas o privadas, se ven enfrentadas a la necesidad del cambio cultural porque está en riesgo su supervivencia. Hoy es habitual que el Estadoy, en particular, su Administración, se vean enfrentados a la solución de los problemasllamados "perversos", como los efectos de la globalización, la demanda y la protesta sociales en franco crecimiento, debido al deterioro económico causado por la pandemia, con los consiguientes reclamos gremiales, la aceleración de la innovación tecnológica, la expansión generalizada del llamado "teletrabajo", la falta de motivacióno de desempeño eficiente de los agentes públicos, el activismo judicial, la militancia política de los medios de comunicación, la corrupción en el sector público, la inseguridad, el narcotráfico y la violencia de género 
en franco crecimiento; en definitiva, un conjunto de hechos de conocimiento notorio, que afligen a la sociedad y acosan al Estado, con el riesgo de introducirlo en la categoría de "fracasado", dejando desprotegida e indefensa a la población.

El referido cambio de la cultura organizacional requiere un previo análisis de sus elementos componentes para posibilitar su modificación con resultado positivo. En ese sentido, la teoría identifica las creencias, los comportamientos y los llamados "supuestos". Las primeras configuran un subsistema de valores y expectativas, consciente o inconsciente, que sirven de modelo o estándar, que los miembros de unaorganización utilizan para determinar lo que está bien o mal, verdadero o falso, importante o irrelevante. La creencia suele cumplir el papel de una fuente acerca de qué pensar, decir y obrar y, en este aspecto, para un empleado público no es lo mismo, atender al público movido por la creencia de que el administrado es un quejoso que conviene eludir o desalentar, que asumir convencido el deber de brindarle un servicio útil y de calidad.

Con relación al "obrar" o el "decir", o sea, las acciones que el grupo desarrolla, configuran los "comportamientos" y son efecto de las creencias, como la vestimenta, el modo de hablar, el tratamiento de los desconocidos o de quienes tienen una posición inferior en la escala jerárquica, el modo de reaccionar ante los conflictos y toda una gama de conductas que pueden derivar de las creencias y que revisten un carácter objetivo y verificable.

Por su parte, los "supuestos" son las razones, pretextos o justificaciones, que mueven a las personas a adherirse a ciertas creencias y comportarse de acuerdo con ellas. Si los comportamientos son exitosos, las personas que forman parte de una organización tienden a repetirlos y los convierten en "rutinas".

En la Administración Pública es frecuente el dato cultural de la resistencia al cambio, que suele expresarse con muletillas conocidas dirigidas a los administrados: "éste es el modo en que hacemos las cosas aquí", "hay reglas que no están escritas, pero están vigentes", "aplicamos políticas extraoficiales" o "este es el criterio de la repartición", aunque se trate de un ritualismo claramente inútil.

La escuela de "Ontología del Lenguaje" aporta otro punto de vista actual sobre las organizaciones, considerando que tanto las públicas como las privadas, pueden ser comprendidas en la medida que constituyen "redes de conversaciones", ya que en su gestión diaria su comunicación tiene lugar a través de un fluir de pedidos, ofertas, promesas, declaraciones y decisiones.

Conforme a esa línea de análisis, se destaca que el "conversar" consiste en una acción articulada entre cuerpo, emoción y lenguaje, desenvuelta por los integrantes de una organización, en las relaciones internas y externas de esta última, existiendo una ingeniería de conversaciones, en su mayor parte de carácter tácito,que no figuran en un organigrama, pero resultan de gran relevancia para lograr objetivos colectivos e individuales, si se saben gestionar. Gran parte de las redes están están sustentadas en la confianza, que es un activo intangible de difícil construcción y consolidación, expuesto al riesgo de pérdida en muy poco tiempo si se lo trata en forma incorrecta. En tal sentido, el "estilo" de conversar se modela a lo largo de la historia de las personas y las organizaciones, directamente conectado a uncierto grado de eficacia y bienestar. En cambio, la falta o el desajuste de las conversaciones dificulta o impide la creación de 
nuevas posibilidades de acción; en particular, las organizaciones en el presente, están sujetas de modo permanente a procesos de rediseño e innovación conectados a los desafíos del aprendizaje y la capacitación y, en definitiva, a la transformación de su marco cultural.

\section{El agente estatal}

La actividad de los agentes públicos y su vinculación con el Estado estuvo influenciada, como explica Fiorini (1976),

por conceptos políticos e ideológicos del pasado", que no reconocían su naturaleza contractual y dieron lugar a una terminología "promiscua", con el empleo de los vocablos "autoridades", autoridades públicas", "funcionarios públicos", "agentes de la administración", "empleados", "personal de servicio", "personal jerarquizado", y luego, con la aparición del Estado empresario, al uso de las categorías de "obreros estatales" y "obreros de servicios públicos" (p. 771).

En ese escenario, se impone una primera distinción entre la posición de los titulares de los Poderes Ejecutivo, Legislativo y Judicial, cuya competencia funcional, compuesta de atribuciones y deberes, en Argentina y conforme a su organización federal de gobierno, se establece en la Constitución Nacional (CNA), las constituciones provinciales y la propia de la Ciudad Autónoma de Buenos Aires, sin que tales titulares estén vinculados al Estado con relaciones de empleo ni derivadas de contratos administrativos.

La tradicional partición entre "funcionarios" y "empleados" también carece de precisión ante la evolución desde el Estado "gendarme" hacia el actual Estado "plurifuncional", que opera también como actor económico, social y cultural, a través de los papeles de empresario, prestador, promotor y competidor, mucho más allá de su rol subsidiario de la actividad privada, en especial, cuando debe afrontar situaciones de emergencia, como la actual pandemia en que se ha acentuado notablemente su acción intervencionista y reguladora, con un perfil autoritario y lesivo de los derechos personales.

En el actual Estado "plurifuncional", la relación de empleo público aparece regulada por un marco normativo de alta densidad formado por leyes, reglamentos e incluso a través de convenios colectivos de trabajo, que en todos los casos presuponen la libertad concurrente del agente para la celebración del contrato que lo vincula con la Administración y que puede adoptar distintas figuras jurídicas, pero siempre excluyendo la aplicación del viejo modelo de las cargas públicas.

La referida introducción de los convenios colectivos en las relaciones de la Administración con sus agentes, no implica la privatización de las mismas, ya que el derecho laboral y su finalidad de protección social a través de normas obligatorias (llamadas en forma equívoca "de orden público", sin que nada se agregue a su obligatoriedad), no puede ser ubicado totalmente en el derecho privado. No obstante, corresponde reconocer que, en la jurisprudencia de mi país, existe cierta indecisión sobre la competencia que debe entender en las cuestiones de empleo público, o sea, si es la justicia laboral o la contencioso-administrativa. 
Los agentes públicos prestan sus servicios en un marco jurídico integrado por los valores, principios y normas constitucionales, las leyes, sus reglamentos administrativos complementarios y las convenciones colectivas del sector laboral público. El diseño de ese marco tiene como presupuesto básico el reconocimiento de la dignidad del trabajador, sea público o privado, con el plexo de los derechos conectados a ella, que son: condiciones equitativas de labor, jornada limitada, descanso y vacaciones pagadas, retribución justa, salario mínimo vital móvil, igual remuneración por igual tarea, organización sindical libre y democrática, recepción de los beneficios de la seguridad social, consistentes en las jubilaciones y pensiones móviles, la protección integral de la familia, la defensa del bien de familia, la compensación económica familiar y el acceso a una vivienda. Tal listado de los derechos reconocidos, al que se agrega la estabilidad en el empleo público, figura en el art. 14 bis de la CNA y en normas similares de las constituciones de numerosos países.

La relación de empleo público con el objeto del deber de prestación del agente,se reitera que responde a una decisión voluntaria del mismo, establecida en condiciónde su ingreso a la Administración, con lo cual se distingue claramente de las funciones impuestas en forma unilateral por el Estado, conocidas con el nombre de "cargas públicas", como son los casos del servicio militar obligatorio o el desempeño de un titular de mesa, en el proceso de elecciones públicas.

Cabe agregar que el empleo público puede adoptar distintas figuras jurídicas y,en ese sentido, pueden señalarse las siguientes:

- la de quienes pertenecen a la planta permanente, con el derecho conexo a la estabilidad;

- la del "personal contratado", con una finalidad específica y por tiempo determinado. En mi país esta práctica ha desnaturalizado la carrera administrativa, ya que los agentes se contratan por un año y se renueva reiteradamente la relación por el mismo tiempo, sin concurso;

- la del nombrado "ad honorem" para realizar un cometido concreto, sin retribución;

- la del personal ajeno al sistema civil, que son los casos de quienes se desempeñan en las fuerzas armadas y de seguridad, que están regidos por regímenes legales propios.

La regulación de los derechos y obligaciones del personal del servicio civil del Estado, comprende a la Administración centralizada y descentralizada, con la aclaración de que, con relación a esta última, se suelen adoptar estatutos o regímenesespeciales para sus empleados.

Sin vínculo contractual figuran las designaciones de carácter "honorario" provenientes de actos unilaterales del Estado, como premio o reconocimiento en favorde una persona, por su acción destacada en favor del interés general, quien a lo sumo, tiene deberes protocolares o de cortesía, sin carácter de obligación legal.

También entre los trabajadores del Estado, se ubica el personal obrero de las empresas estatales, que está sujeto al derecho laboral y a los convenios colectivos enla materia. En esa línea, con relación a los entes reguladores de servicios públicos de Argentina, que tienen carácter de entidades autárquicas, se considera que, salvo su personal directivo, el resto de sus empleados tiene relaciones de índole laboral. 
El servicio civil de la Administración se desenvuelve a través de una "carrera administrativa", que es una organización compuesta de grados, clases, grupos, categorías o niveles jerárquicos, cada uno con sus propios derechos y obligaciones. Éstos suelen estar previstos en regímenes generales o especiales por actividad, que tienden a establecer pautas de claridad y seguridad en las relaciones entre el Estadoy sus agentes. Corresponde señalar que las personas que se desempeñan en los Poderes Legislativo y Judicial son ajenas al servicio civil y su actividad está regulada por regímenes especiales.

Con relación a las atribuciones y deberes propios de las funciones de los agentes de la Administración Pública, debe recordarse que los mismos actúan dentro de un subsistema dentro del sistema estatal, sin que hoy se discuta que el Estado tiene la capacidad de una persona jurídica y la organización administrativa forma parte de él, es decir, que el concepto de capacidad está unido al de sujeto, mientras que la competencia está conectada a la noción de órgano, siendo esta última una asignación parcial de fines y medios, dentro del marco de la capacidad.

Por su parte, cuando un órgano de la Administración ejercita su competencia pone de manifiesto atribuciones y deberes que suelen ser correlativos de derechos y obligaciones de los administrados. En la doctrina se destaca ese doble aspecto de la competencia, uno frente a las relaciones con los administrados y otro con la mirada dirigida hacia el reparto del trabajo en lo interno de la organización administrativa, señalándose que, en rigor, la competencia sólo funciona en lo externo (a través de lasrelaciones de "exoestructura", según la teoría sistémica), mientras que en lo interno sólo se da atribución de funciones a subórganos o agentes (división del trabajo o relaciones de "endoestructura").

En un trabajo anterior ${ }^{2}$ expresé que no comparto esa visión restrictiva porque ami entender, los órganos de la administración interna que intervienen en el proceso de decisión de un acto, también tienen competencia, como también, los "cargos" o "puestos" de trabajo que están insertados en cada órgano, con cierta libertad del superior jerárquico en la distribución de tareas, pero con límites de especialización funcional (v. gr. no se puede requerir a un ordenanza que elabore un dictamen jurídico).

A lo sumo, la distinción podría tener utilidad en la discutida cuestión sobre los conceptos de funcionario y empleado, si se atribuyera al primero la potestad de decisión en las relaciones con los administrados.

En la organización del Estado, la competencia no responde exclusivamente a los principios de especialización y jerarquía, sino también a otras relaciones de nivel constitucional entre los poderes, como las de "supremacía" y "primacía", en el caso, por ejemplo, de la CNA, siendo las primeras generadas por el presidente, conforme a su carácter de jefe del gobierno, en sus vínculos con los poderes legislativo y judicial, las naciones extranjeras y los gobiernos autónomos de las provincias y la Ciudad de Buenos Aires. Las segundas, por su parte, son las que tienen lugar entre el presidentey el jefe de gabinete, el presidente y los ministros y el jefe de gabinete y los ministros. También incluyen el control de tutela de la administración centralizada sobre la descentralizada (Conf. CNA, arts. 99, incs. 1), 3), 4,) 7), 9), 100 y ccss.).

2 V.MATA, Ismael, “La competencia como requisito esencial del acto administrativo (desde la visión sistémica y económica)”, en "Ensayos de Derecho Administrativo", Ediciones RAP, Buenos Aires, 2009,pp. 193/202. 
Para el análisis de la relación del agente público de una Administración Servicial y con una modalidad de trabajo a distancia, corresponde recordar ciertos caracteres de su posición jurídica, en particular:

- el deber del desempeño personal de las actividades propias de su cargo, sin que puedan ser realizadas por una persona jurídica, ni tampoco a título de representante o mandatario;

- sus funciones deben ser ejercidas dentro del marco de su competencia, con las precisiones formuladas precedentemente;

- su actuación exige requisitos objetivos de "idoneidad" en los aspectos técnicos y morales, pero sin los rasgos de un vínculo "intuitu personae";

- las reglas de selección, ingreso, prestación del servicio, retribución, régimen disciplinario, licencias, beneficios sociales y demás condiciones laborales, están previstas en un marco normativo al que ya me referí.

En la Administración actual, que se encuentra sometida a un intenso proceso de transformación, corresponde atender a la situación del personal permanente que goza de la garantía de la estabilidad, adquirida luego de un desempeño temporal de prueba legalmente establecido, de manera que luego de consolidado el derecho, el agente sólo puede ser removido por justa causa. Por lo tanto, se plantea un problema de difícil solución cuando la Administración necesita proceder a una reestructuración orgánica en la que no tiene cabida el agente con estabilidad. En ese caso, se intenta su reubicación en otro sector o bien, su colocación en posición de disponibilidad porun tiempo determinado y, luego de su transcurso, se procede a su remoción con el pago de una indemnización.

La remodelación de la Administración Pública para lograr un profundo cambio de su cultura, eficiencia y eficacia, transformándola en una organización servicial, requiere además inevitablemente, la realización de los objetivos concurrentes que sonla revalorización, capacitación y respeto de sus derechos, de los agentes públicospara que se integren con vocación de servicio a esa nueva Administración.

\section{Administración y tecnología digital}

El intenso avance de la tecnología y la mejor comprensión de las relaciones humanas, tanto en lo interno como en el ámbito externo de las organizaciones, han asignado un papel preponderante a la información y a las nuevas formas de pensamiento que su desarrollo genera. En tal sentido, corresponde identificar al "dato"como unidad primaria de información en sus cuatro formatos de palabras, números, sonidos e imágenes, los cuales se almacenan y procesan conforme a un patrón ordenador, que les asigna un sentido específico. Así, por ejemplo, los números son datos, pero aplicados a un cuadro estadístico de proyecciones, constituyeninformación, que es el insumo básico para la toma de decisiones.

A su vez, cuando la información es recibida y comprendida por sus destinatarios, se transforma en conocimiento, que es el empleo y aplicación útil de la información, como sucede, por ejemplo, con los datos "sonidos", cuando se transforman en notas y se combinan en un sistema que produce música. 
Por último, cuando es compartida, poniéndose en común con otras personas, da lugar a la comunicación, que es un proceso continuado, iniciado con un "mensaje portador" de un objeto dotado de "significado", que permite su "decodificación" por los destinatarios. Con ello se posibilita que los miembros de una organización trabajen y cooperen entre sí, identifiquen las necesidades y tiendan a lograr los objetivos previstos.

La gestión administrativa y su regulación normativa se han visto profundamente transformadas por el impacto de la aceleración tecnológica en el escenario global de la "Sociedad de la Información", cuyos recursos permiten en forma inmediata obtener información y decidir a través de la "red de redes" (Internet) en cuyo ámbito tienen lugar casi todas las clases de información y decisión, planteando a una Administración Servicial el desafío de tomar decisiones eficaces a través de la aplicación ineludible de las nuevas tecnologías, para lo cual se requiere la capacitación permanente de sus agentes. El nuevo modelo consiste en la asociación de tecnologías de la información y la electrónica, integrando el fenómeno llamado "convergencia tecnológica", es decir, la concurrencia, que indiqué precedentemente sobre Internet, de la mayor parte de lasactividades económicas, sociales y culturales, configurándose el "hipersector de la información".

De acuerdo con esos objetivos, los países vienen adoptando para el sector público una progresiva política de "despapelización", tanto en su ámbito interno como en la relación con los administrados, a través del propósito anunciado, de mejorar su gestión, facilitar el acceso de la comunidad a la información pública y lograr que la realización de los trámites resulte segura y efectiva.

En materia de documentos digitales se ha establecido el reconocimiento y uso de los certificados emitidos por certificadores reconocidos, previéndose incluso la posibilidad de su emisión por agentes públicos autorizados, en asuntos vinculadoscon la gestión de sus organismos de revista. No obstante, debe reconocerse que en Latinoamérica, la aplicación de las nuevas tecnologías, antes y durante la pandemia, todavía muestra cierta lentitud y carece de unidad en el sector público, sin separación plena de las actuaciones escritas y con frecuentes caídas en el funcionamiento de los sistemas. El abordaje informático también fue materia de planes para la promoción delas Tecnologías de la Información y la Comunicación (TICs), dirigida a los sectores público y privado, exhibiendo un escaso grado de maduración en el primero.

En Argentina, se dio un paso importante con la aprobación del régimen generalde contratos públicos, en el cual se dispuso, para asegurar el principio de "transparencia", que la publicidad y difusión de las demandas tuvieran lugar mediante el uso de tecnologías informáticas. Asimismo, se incorporaron las contrataciones de formato digital, con la recepción por la Administración a través de esa vía, de ofertas, informes, documentos, comunicaciones, impugnaciones y recursos, relacionados con el procedimiento de selección. En otras palabras, las actuaciones presentadas en formato digital tienen igual valor legal que los documentos en soporte papel y firma manuscrita (Decreto Delegado 1023/2001).

La gestión de la Administración debe desenvolverse en un ámbito social que actualmente se caracteriza por una abrumadora masa de datos que inciden sobre la vida de las personas en todos sus aspectos, requiriendo un tratamiento ordenador a través de las nuevas tecnologías, que hacen posible su almacenamiento y sistematización, 
conocidos como "Big Data" más "Data Mining" (minería de datos),que posibilita la toma de decisiones dotadas de mayor eficacia, sustentadas no sóloen variables pasadas, sino también en predicciones a futuro, con bases científicas de mayor solidez.

La información que se obtiene por medio del sistema de "Big Data-Data Mining", en razón de sus caracteres de calidad, precisión y utilidad dirigida hacia los objetivos propuestos, permite dar un paso más en los procesos decisorios, que consiste en la aplicación de "Inteligencia Artificial", modelo que apunta a imitar y aún superar el razonamiento humano mediante la implementación de algoritmos, cuyo concepto data del Siglo IX en Persia y recién en el Siglo XVIII se lo utilizó para resolver problemas. Su evolución dio un paso decisivo cuando se programó para su aprendizaje automático ("machine learning"), es decir, la capacidad de aprender por símismo, que en su versión avanzada ("aprendizaje profundo") procura funcionar como el discurrir humano.

La actuación de la Administración en el escenario de la "Sociedad de la Información" y la necesidad de aplicar las nuevas tecnologías, debe desenvolverse enun contexto social de alta complejidad, caracterizado, entre otras, por las cuestiones siguientes:

- el aumento de la demanda y la conflictividad sociales, agravadas por los fenómenos globales de crisis financieras y económicas y la reciente pandemia, sin final previsible;

- la mayor exigencia de que el Estado provea "bienes públicos" y proceda a la satisfacción de la demanda social;

- el efecto ambiental negativo producido por las deseconomías externas, derivadas de las actividades de producción y consumo;

- las asimetrías informativas de la propia Administración, generadas por las fallasde sus sistemas y una regulación inadecuada frente a los comportamientos estratégicos de los operadores sectoriales;

- las dificultades cada vez más frecuentes para resolver los llamados "problemas perversos", que a diferencia de los "dóciles", la solución que se adopta se suele transformar en un nuevo conflicto, como suele acontecer, por ejemplo, con el tratamiento desigual de las jubilaciones, la ocupación del espacio público por la protesta social ante la libertad de circulación y, en general, la enorme cantidad de disyuntivas que deben ser resueltas en el ejercicio de la función pública.

Las nuevas tecnologías y un mejor tratamiento de las relaciones humanas, tanto en lo interno como en lo externo de las organizaciones, han impulsado el rediseño de los procesos decisorios, que exigieron cambios profundos en la Cienciade la Administración.

En tal sentido, resulta menester que el Estado y su Administración, al igual que cualquier organización -sea pública o privada- debe emplear la técnica de la planificación, previendo acciones futuras y sostenidas en el tiempo para lograr objetivos específicos en beneficio del interés general. Con ello, a mi entender, resulta claro que la planificación implica el comienzo de los procesos decisorios en el sector público, procurando encontrar solución a los problemas identificados a través de la previsión, que es el primer paso en la tarea de planificar y que se configura como un conjunto de procedimientos decisorios articulados entre sí y dirigidos a los puntos de convergencia, que consisten en los planes específicos. 
Por otra parte, las previsiones de la planificación sirven como las pautas de control que condicionan todas las decisiones y actividades futuras de la organización, formando parte del estándar, rol o modelo que debe seguirse, como se advierte con los vocablos "contre rôle" de origen francés, que alude a la confrontación del acto de gestión con la regla, en nuestro caso, la establecida en el plan para verificar su cumplimiento, las desviaciones y sus posibles correcciones.

Las decisiones de la Administración se toman mediante actos de alcance general o individual, con sujeción a las reglas del procedimiento administrativo, que constituyen el presupuesto esencial de la decisión, respondiendo a los principios de juridicidad y legalidad. El primero, determina que toda actividad estatal debe estar sostenida por un sistema integrado de valores, principios, normas y técnicas, mientrasque la legalidad es una garantía que condiciona la ejecución de las funciones y actividades estatales, asegurando el reconocimiento de los derechos personales.

En Argentina, sobre los procesos decisorios de la Administración gravitan los principios de participación e información ciudadana, acerca de los cuales la reforma constitucional de 1994, introdujo relevantes figuras jurídicas, como la "iniciativa popular" (CNA, art. 40); la "necesaria participación de las asociaciones deconsumidores y usuarios"..."en los organismos de control de los servicios públicos"(íd. art. 42); la legitimación procesal en el amparo de las asociaciones dedicadas a la protección de los derechos relativos al ambiente, la competencia, al usuario y al consumidor, así como a cualquier persona cuando aparezca afectada la libertad personal (íd. art. 43); la participación de la familia y la sociedad en la legislación educativa (íd. art. 75, inc. 19); y las figuras de participación previstas en los tratados internacionales sobre derechos humanos (íd. art. 75, inc. 22). También se establecióel acceso a la información pública en materia ambiental y a favor de los consumidoresy usuarios de servicios, con la prescripción en este segundo supuesto, de que la misma sea "adecuada y veraz" (íd. arts. 41 y 42).

El órgano competente o "procesador" debe disponer o elaborar distintas posibilidades de decisión, ejerciendo en determinados casos atribuciones discrecionales que le permiten elegir entre alternativas igualmente válidas en derecho (que se califican de "indiferentes jurídicos").

Por lo tanto, de acuerdo con lo expuesto, el acto de elección debe reunir las condiciones siguientes:

- cumplimiento de las reglas de procedimiento administrativo;

- el diseño del objeto o núcleo de la decisión que responda a un "modelo de desempeño", con la justificación de su factibilidad jurídica y la satisfacción del fin público específico;

- instrumentación de la decisión con ajuste a los requisitos legales, expresando las razones que respaldan su emisión (motivación); y

- producción de efectos (eficacia), una vez producido su examen sin objeciones por los órganos de control, así como su comunicación a quienes tengan interéso derecho en ella o bien su publicación, si el interés tuviera carácter general.

Además de la eficiencia, que es la articulación de los factores de buena administración en lo interno de la organización que concurren en la construcción de una decisión, es 
menester el logro de sus resultados (eficacia), ya que a veces ambosrequisitos no se cumplen satisfactoriamente. Cabe agregar que el ingreso de los efectos al ámbito externo pone en marcha el procedimiento de "retroalimentación", a cargo de los órganos de control o de planificación y aún de la comunidad a través de mecanismos crecientes de participación, que miden el mérito de la decisión.

A comienzos de la década del 80 del siglo pasado, Inglaterra adoptó el Estatutodel Ciudadano como parte de su programa de Reforma del Estado, con el propósitode mejorar la relación con los usuarios de servicios públicos, aplicando políticas de gestión usuales en el sector privado, con un lema de promoción que era: "lo primeroes el cliente". De acuerdo con ese propósito, se pusieron en práctica distintos estatutos sectoriales, como los de Pasajeros, Contribuyentes, Viajeros, Subsidio de Desempleo, Inquilinos, Pacientes e incluso de litigantes en tribunales, con invocación de los principios inspiradores de "Niveles de Calidad", "Información y Transparencia”, "Cortesía y Amabilidad” y "Corrección de las Fallas".

Numerosos países adoptaron el modelo consistente en obligaciones específicas hacia sus habitantes, contenidas en Estatutos al estilo inglés o en "Cartas-Compromiso con el Ciudadano", como el caso de Argentina, agregando a los deberes previstos en la competencia de sus autoridades, indicadores concretos y cuantificados de calidad y eficiencia -calificados de "estándares"- para las actividades y servicios públicos a cargo del Estado, aspirando a la satisfacción efectiva de las necesidades de la gente.

En esa línea, el acto de institución de la referida "Carta Compromiso" de Argentina, en sus fundamentos se señalaba que el programa de mejora de los servicios no debía limitarse a "una declaración formal de intenciones, sin ningún efecto operativo", por lo tanto, la Administración se obligaba a dar publicidad a los estándares de calidad, así como a los compromisos de mejorarlos, estableciendo un verdadero "contrato AdministraciónCiudadano", por el cual la organización pública generaría credibilidad en la sociedad. El elemento central de la Carta -según se anunciaba- es la obligación que la Administración hace pública de prestar, de prestar sus servicios de manera satisfactoria, atendiendo a las expectativas de la gente, osea, concretamente, lo que necesitan y esperan (Debo agregar que tan encomiables propósitos no fueron llevados a la práctica, pasando a ser un fenómeno cultural más de la "magia de las palabras").

Resulta interesante señalar que los estándares se elaboran y se ponen en práctica con mecanismos de participación, en primer lugar, de los agentes de la Administración que son consultados, formulan propuestas $\mathrm{y}$, finalmente, asumen el compromiso de cumplirlos. El diseño de los estándares con intervención del personal desde abajo hacia arriba en la escala jerárquica, constituye un poderoso factor de cambio cultural, unido a la participación de la comunidad en su diseño, a través del pedido de opiniones e iniciativas dirigido a los destinatarios de la actividad estatal.

El proceso de diseño y aplicación de estándares debe tener los caracteres de continuidad y dinamismo, ya que requiere la actualización periódica de los indicadores de calidad comprometidos, con participación y consulta a especialistas, por lo tanto, en la preparación del programa y en su proceso de ajuste, corresponde acudirse a un sistema de información y comunicación con el ciudadano, que posibilite la eficacia de las acciones de gobierno, la legitimación de la gestión administrativa, la transparencia de los actos del Estado y la identificación de lo que necesita y espera la gente. 
En un trabajo anterior, expresé que resulta necesario generar, en sentido ascendente, participación, iniciativa, expresión de opiniones, compromiso y sentido de pertenencia del personal que integra la Administración, aplicando una cuidadosa metodología y técnicas de dinámica grupal. En definitiva, se trata de reordenar en el marco negativo de la pandemia y más aún, de modificar las creencias, los comportamientos y los presupuestos de la cultura estatal, para orientarlos firmemente hacia los objetivos de la deseada Administración Servicial.

En el inevitable derrotero de la Administración y sus agentes hacia su tecnificación digital y el teletrabajo, al impulso impuesto por la pandemia, correspondeformular algunas prevenciones para no olvidar que una Administración Servicial necesita de un rostro y una comprensión claramente humanos, dirigidos hacia la gente, ya que la fuerte expansión de la comunicación virtual, está dando lugar a un fenómeno disvalioso que comienza a calificarse de "exclusión digital".

Tal efecto consiste en los fuertes límites o barreras que se están produciendo en el acceso a las nuevas tecnologías para gran parte de la población, sea por faltade recursos que posibiliten disponer del equipamiento o por factores generacionales oculturales, que obligan a pedir ayuda en trámites, operaciones o gestiones, muchas veces sin tener otro interlocutor que una máquina.

Por lo tanto, resulta una responsabilidad primaria de la Administración la adopción de una política de gradualismo hacia la aplicación de las nuevas tecnologíasen las relaciones con los administrados, reabriendo los canales presenciales prematuramente cerrados y ofreciendo un rostro humano comprensivo y útil, que permita superar tan deplorable factor de discriminación.

En definitiva, la visión del futuro sobre el impacto de la tecnología sobre nuestra vida, como toda percepción humana, exhibe diferencias y aún contradicciones, que, según los medios de comunicación, pueden agruparse del modo siguiente:

1. tecno-optimista, que imagina acciones públicas y privadas con el objetivo de mejorar la calidad de vida de la gente;

2. tecno-autoritaria, con la mirada puesta en algunos Estados, como China y Rusia; y

3. tecno-capitalista o "de la vigilancia", según la cual, las empresas manejan la información relativa a las personas para venderles sus bienes y servicios.

La transformación profunda de la vida social a través de la tecnología ha permitido en la crisis de la pandemia, usar las impresiones 3D para la preparación de máscaras, hisopos para pruebas, respiradores y diversos elementos técnicos. Robots y drones se emplean en el control del aislamiento, el patrullaje de los movimientos degente en las calles y, a distancia, sobre los enfermos de Covid 19. En particular, las nuevas tecnologías han posibilitado que, en pocos meses, puedan elaborarse vacunas, cuando en los tiempos anteriores a la pandemia, se necesitaban alrededor de diez años.

Con relación a la visión optimista, puede ubicarse el modelo empresario de "triple impacto", que aspira a integrar el desarrollo técnico, económico y social con la protección del ambiente, por medio de una gestión orientada a brindar bienes socialesy ambientales, sumados a los de carácter económico. No faltan quienes, a través delos medios, opinan 
que después de los padecimientos provocados por la pandemia, lasociedad se encamina hacia un fortalecimiento de la solidaridad, por cuanto la necesidad de enfrentar la enfermedad ha generado un sentimiento general de protección y cuidado mutuo.

En lo tocante al modelo autoritario, resulta claro que el arsenal de medios tecnológicos disponibles puede contribuir a la instalación y fortalecimiento de gobiernos de ese carácter. En cuanto a los recientes instrumentos aplicables, puede señalarse que en China y otros países, se aplican el reconocimiento facial, cámaras térmicas y pulseras electrónicas, para detectar a los enfermos afectados por el virus.

En el ámbito de Iberoamérica, no puedo dejar de mencionar el riesgo de los gobiernos de corte populista, que pueden tratar de instalar de modo permanente los avances sobre los derechos personales, realizados con invocación de la pandemia.

En cuanto a la visión "tecnocapitalista", la calificada socióloga y filósofa Shoshana Zuboff, profesora emérita de la Harvard Business School, señala que en el "siglo digital", el "capitalismo de vigilancia", ha provocado que las empresas tecnológicas utilicen el conocimiento y la información que obtienen "para que la gente piense, diga y haga cosas que normalmente no habría hecho" y ese proceso nocivose agudizó con la "carte blanche" que dichas empresas recibieron después del atentado 11/09/2001, registrándose posteriores sucesos como el escándalo de Cambridge Analytica. Asimismo, señala que el posible remedio a los avances de los que llama Gigantes digitales -V. gr. Facebook, Google, Amazon-, sería según sus palabras: "traer los derechos, las leyes y las instituciones de supervisión a este siglo,si queremos tener un siglo digital que sea compatible con la democracia" ${ }^{3} 4$.

Cualquiera sea la mirada del futuro, resulta inevitable destacar que se producirá un incontenible avance de la inteligencia artificial, como producto de varios componentes, que funcionan en forma conjunta y que son:

- el desarrollo tecnológico;

- la infraestructura física de los cables submarinos (cuya extensión en kilómetrosda 28 vueltas a la Tierra);

- centenares de centros de almacenamiento de datos con alrededor de diez empresas propietarias;

- un consumo de energía por grandes empresas de tecnología, que generan un volumen de gas invernadero, equivalente al de toda la industria aérea antes de la pandemia;

- un universo de personas cada vez más conectadas, dando lugar a un llamado "escape digital", que captura y registra casi todos los datos de nuestra vida ${ }^{4}$.

3 Entrevista del día 24/04/2021, en el diario "La Nación" de Buenos Aires.

4 V. PETRELLA, Iván, "Mundo tecno ¿Adónde nos está llevando la inteligencia artificial?", en "La Nación” de Buenos Aires, 17/04/2021. 


\section{El Trabajo a Distancia ("Teletrabajo”)}

Uno de los efectos más notables producidos en el marco de la pandemia es la consolidación del trabajo remoto o a distancia y al parecer, según encuestas realizadas, las empresas privadas opinan que les ha resultado beneficioso. Por su lado, una tercera parte de los trabajadores encuestados expresan que renunciarían a su empleo si tuvieran que regresar a su oficina a tiempo completo.

Por lo tanto, ante el nuevo escenario, en el sector privado, las empresas han adoptado distintas estrategias para el regreso de su personal, en forma articulada conel teletrabajo, como, entre otras, acentuando las medidas de seguridad en salud, proveyendo una información útil, una efectiva disposición a escuchar sus pedidos, y asegurando que los lugares de trabajo sean limpios, asépticos y cómodos.

En esa línea de acciones, puede advertirse que tiene gran relevancia la puesta en marcha de una política de estándares de calidad, que ya referí en el Capítulo 2 de este trabajo. Cabe asimismo destacar la importancia de las normas destinadas a los agentes públicos, con su posible incorporación por la vía de los convenios colectivos, que son complementarios de las normas legales estatutarias del empleo público.

Debe destacarse que el "teletrabajo" es sólo una modalidad del trabajo a distancia, que supone el desempeño en un lugar diferente de la sede del trabajo, caracterizado por la aplicación de tecnologías informáticas, aunque pudiendo adoptar un perfil mixto con combinación de prestaciones presenciales.

Con miras a su aplicación en la relación de empleo público, sería importante incorporar los incentivos para lograr que el nuevo sistema de labor sea acompañado mediante programas de bienestar del personal, de apoyo familiar -v. gr. guarderías para sus hijos-, de capacitación informática, de actividad física y similares de índole social. Si bien la nueva modalidad de "teletrabajo" registraba algunos antecedentes antes de la pandemia, con ensayos de regulación para el sector laboral privado motivados por la acción sindical, aparecieron algunas pautas de la legislación laboral reciente, que pueden ser de utilidad para el sector público, como las indicadas a continuación:

- Establecer la igualdad de derechos entre agentes presenciales y nopresenciales, sin que la remuneración de éstos sea inferior a la que reciben losprimeros.

- El cambio desde una posición presencial a la modalidad de teletrabajo debe ser voluntario y puede ser revocado en cualquier momento, siempre que no se afecten las tareas en curso de ejecución (principio de reversibilidad).

- En tal caso, la prestación se realizará en el mismo lugar en que el agente se hubiera desempeñado con anterioridad o, en otro, lo más cercano posible a su domicilio.

- De todos modos, el regreso a la posición presencial debe ser comunicada por el agente con razonable anticipación, para permitir que la Administración adopte medidas de reorganización.

- La jornada laboral debe estar claramente establecida, sin que se pueda exigiral agente la realización de tareas fuera de esa jornada, salvo que existiera una razón justificada de urgencia. 
- La persona que opera conforme a esa modalidad tiene el derecho a desconectarse fuera de su jornada laboral y en sus períodos de licencia.

- Los agentes que tengan responsabilidades familiares de cuidar a personas menores, discapacitadas o adultos mayores, que convivan con ellos y requieran asistencia, tendrán derecho a condiciones de trabajo y horarios acordes con sus deberes de asistencia.

- La Administración debe proveer al empleado el equipamiento -hardware y software- y demás elementos de trabajo para la realización de su trabajo, haciéndose cargo de los gastos de instalación, mantenimiento y reparación de los mismos.

- Por su parte, el empleado asumirá la responsabilidad por el uso correcto y el mantenimiento adecuado de los elementos provistos, evitando su uso por personas ajenas a su relación de trabajo. En caso de desperfectos, roturas o desgastes de tales elementos, la Administración atenderá su reemplazo o reparación para asegurar la continuidad de las tareas. Durante el tiempo que requieran tales trabajos corresponde mantener la integridad del salario del agente.

- Puede darse la posibilidad de que el empleado realice su trabajo con instrumentos propios, debiéndose fijar las condiciones en ese supuesto.

- El empleado tendrá el derecho a la compensación de los mayores gastos por la conectividad y el consumo de los servicios necesarios para realizar su trabajo.

- Se requiere un sistema de protección de datos que preserve los intereses propios de la Administración y la intimidad y los datos personales del agente.

- Deberá procederse a la adaptación de las reglas de higiene y seguridad en el trabajo a esta nueva modalidad, así como a las vinculadas con los accidentes que pueden producirse en el lugar, la jornada o en ocasión del cumplimiento delas tareas.

\section{Estado y emergencia}

Los Estados durante la pandemia impusieron medidas de aislamiento y distancia, así como un fuerte control digital sobre sus habitantes, generando el uso masivo de la comunicación a través de videoconferencias, con lo cual quedaron expuestos los datos personales, produciéndose un avance significativo sobre el ámbito de la privacidad y el papel protagónico de las grandes corporaciones informáticas. Como ya mencioné precedentemente, el sonado caso de Cambridge Analytica y su uso clandestino de los datos de 50 millones de usuarios, asombraba a la opinión pública y ponía de manifiesto el poder de dichas corporaciones.

Hace poco tiempo, en publicaciones internacionales, se comentaba que pese alas fallas de seguridad que tenía la videollamada Zoom, desde el comienzo de los aislamientos obligatorios dispuestos con causa en la pandemia, había crecido diariamente un 535\%. Pero, pese a su éxito, esta modalidad de "zoombombing", no ofrece la garantía de seguridad consistente en un sistema cifrado de extremo a extremo, que permite sólo a los usuarios comunicados la lectura de los mensajes. 
Dicha modalidad fue calificada por el Washington Post, como una forma de acoso "online", coherente con el boom de la tecnología de principios de este siglo, donde el objetivo era instalar rápidamente los servicios sin reparar en la cuestión de laseguridad, conforme al lema de Facebook: "moverse rápido y romper cosas", o sea, fallando en lo que se conoce como la "privacidad por diseño".

Si bien el uso del Big Data y la vigilancia digital han dado buenos resultados enlas acciones contra la pandemia, en países con disciplina social como China, Corea, Taiwan, incluso Japón, corresponde preguntarse en el momento de decidir su uso,qué ocurrirá cuando termine la lucha contra la enfermedad, con instrumentos disponibles de gran eficacia para el control social, aunque con impacto de discriminación social sobre los pobres, adultos mayores o inmigrantes.

En ese aspecto, corresponde tener en cuenta las técnicas de geolocación, la información conectada con el uso de las tarjetas de crédito o las pulseras impuestas obligatoriamente en Hong Kong, con aplicaciones que permiten verificar a los agentespúblicos si las personas abandonan su lugar de cuarentena. Además, cabe señalar el papel que desempeñarán las grandes corporaciones en esas futuras tareas de vigilancia, sea operando sólo con la mira puesta en sus propios intereses comerciales o bien, prestando asistencia técnica al Estado.

Así como se discute en doctrina si el uso de los algoritmos o los desarrollos de inteligencia artificial constituyen actividades riesgosas con efectos dañosos, por sus posibles errores, "sesgos" o manipulaciones, los sistemas de control informático que se han puesto en funcionamiento para enfrentar la pandemia, requieren un análisis preventivo y la elaboración de un marco regulatorio bien ponderado, con la finalidad de asegurar su correcto uso, como un paso ineludible en la protección del complejode derechos sustentado en la dignidad humana, entre los cuales se ubica laposibilidad de decidir libremente.

Ante la irrupción imprevista de la pandemia los gobiernos han procedido a la declaración de la emergencia sanitaria por un tiempo determinado, con numerosas renovaciones causadas por la persistencia y la gravedad de la enfermedad. Asimismo, se adoptaron numerosas medidas destinadas a suprimir o atenuar sus efectos, entre las cuales pueden destacarse las indicadas a continuación.

a) Aislación obligatoria durante un tiempo determinado para los casos "sospechosos" de la enfermedad, los confirmados por los médicos y de quienes arriben al país provenientes de zonas afectadas por la pandemia.

b) No pueden permanecer en el país los extranjeros que arriben y no cumplan con el aislamiento obligatorio y las medidas sanitarias establecidas.

c) Ante los casos de incumplimiento de las medidas, los médicos, autoridades y otros actores tienen obligación de denunciarlos.

d) Se autoriza a la contratación directa por el Estado, atendiendo a probadas razones de urgencia.

e) Se designa una autoridad sanitaria para coordinar todas las acciones de lucha para enfrentar la enfermedad con el deber de brindar información diaria sobre los lugares afectados y el estado de la pandemia, manteniendo la confidencialidad de las personas afectadas y la vigencia del secreto profesional. 
f) Denuncia penal contra quien violare las medidas de la autoridad para impedir la introducción o propagación de la pandemia o de quien resistiere o desobedeciere a un funcionario público, en ejercicio de dichas medidas, así como a la persona que lo asistiere.

g) La autoridad sanitaria debe realizar el seguimiento de la evolución de los enfermos y de las personas que tengan contacto con ellos.

h) Imposición de restricciones, totales o parciales, en los lugares públicos e inclusos privados, donde pueden tener lugar reuniones de personas, como, por ejemplo, calles, plazas, cines, teatros, gimnasios, escuelas, templos religiosos, comercios, restaurantes, medios y terminales de transporte, etc.

En definitiva, como puede advertirse se ha configurado un cuadro de serias limitaciones a los derechos personales, dispuestas en la mayor parte de los casos, por los poderes ejecutivos y a veces por órganos administrativos, con invocación de laurgencia y la situación de emergencia generada por la pandemia y en un marco institucional con escasa presencia del legislador y del control judicial.

La situación descripta ha merecido calificadas críticas, como las expresadaspor el filósofo italiano Agamben (2020), quien señala que la transformación impuesta por los poderes "no es un nuevo canon legislativo, sino el estado de excepción, esto es, lamera suspensión de las garantías constitucionales", de modo que

si el dispositivo jurídico-político de la Gran Transformación es el estado de excepción, y su dispositivo religioso, la ciencia, en el plano de las relaciones sociales aquélla ha confiado su eficacia a la tecnología digital, que, como ya es evidente, conforma un sistema con el "distanciamiento social", que define la nueva estructura de las relaciones entre los seres humanos".(...) "Ya desde hace décadas opera una progresiva pérdida de legitimidad de los poderes institucionales, a la que éstos no han sabido poner freno a no ser a través de la producción de una perpetua emergencia y la necesidad de seguridad que ésta genera (pp. 10-12).

A tan severa mirada de la realidad, podemos sumar la opinión de Nancy (2020), quien escribe:

El virus revela por sí mismo un mundo que desde hace largo tiempo yaexperimenta el desconcierto de una mutación profunda. Lo que está en juego no es solamente la organización de las dominaciones, es todo un organismo que se siente enfermo, es una seguridad obstinada en la creencia en el progreso y en la impunidad de la depredación, que es cuestionada, sin que no obstante se presente ninguna convicción nueva en la posibilidad de habitar humanamente el mundo (p. 9).

En la doctrina parece dominar un criterio general consistente en que las medidas adoptadas para responder a la pandemia constituyen una manifestación del mal llamado "poder de policía" del legislador, en este caso, con un amplio margen de delegación en favor de los poderes ejecutivos. En rigor la reglamentación o regulaciónde los derechos personales que es una atribución exclusiva del legislador, puede responder a tres objetivos: 
1. ajustar y coordinar el ejercicio de los derechos individuales para hacerlos compatibles entre sí, a través de una técnica reguladora que puede calificarse como "delimitación";

2. sujetar el ejercicio de los derechos personales al interés público o bien común, aplicando la "limitación" de los mismos; y

3. efectuar una sujeción más estricta de los derechos, cuando sobrevienen situaciones de crisis y emergencias, recurriendo a "restricciones" de los mismos.

Otro enfoque consiste en la "legalidad del recambio" o "de crisis", que opera en sustitución de la legalidad normal, con la aclaración formulada por Laubadère: "La teoría de las circunstancias excepcionales no constituye una laguna, sino un simple correctivo de la legalidad normal".

En síntesis, considero que se trata de distintos grados de intensidad en la regulación, sin que en ningún caso resulte admisible la desnaturalización o alteración de los derechos personales ni de los principios y garantías conectados a ellos.

Pasaré ahora a exponer brevemente la posición de Agamben (2007) sobre el momento en que se suspende la vigencia del derecho, justamente para asegurar su continuidad e incluso su existencia, situación en que, según nuestro autor, aparece la "excepción" fundada en el estado de necesidad, la que no puede asumir una forma jurídica porque está situada en la frontera entre la política y el derecho, en un puntode desequilibrio -similar a la guerra civil, la insurrección o la resistencia a la opresión-, es decir, en la señalada zona incierta y de frontera entre el mundo jurídico y larealidad.

La doctrina alemana emplea, para cubrir los supuestos que se apartan del derecho normal, los conceptos de "estado de excepción" y "notstand", equivalentes alde "estado de necesidad", que en las teorías italiana y francesa no se aplican en el derecho público, empleando, en cambio, los "decretos de necesidad y urgencia" y el "estado de sitio", sumando a este último las calificaciones de "político" o "ficticio".

AGAMBEN puntualiza que el "estado de excepción no es un derecho especial (como puede serlo el derecho de guerra), porque implica una suspensión del propio orden jurídico, constituyendo un umbral o concepto límite, en el cual dentro y fuera no se excluyen, sino que se indeterminan. La suspensión de una norma no provoca su abolición y la zona de anomia que se genera no queda totalmente separada del orden jurídico. Por lo tanto, concluye en que se impone pensar una nueva relación entre lo posible y lo real, ya que no es lo posible que exige ser realizado, sino la realidad que demanda volverse posible.

Por mi parte, me pregunto ante ese juego de palabras, si tiene como significado, juridizar la nueva realidad, con mayor precisión en la regulación de la excepción o ésta es tan compleja y multiforme, que se resiste a la disciplina normativa. Y me permito agregar que no es posible en el derecho argentino y que tampoco, en el derecho iberoamericano (sin incluir a los modelos autoritarios de gobierno), el sostener la posibilidad del "estado de excepción" para afrontar una gravee imprevista necesidad pública, ya que conforme a las constituciones están fijadas losPoderes y sus atribuciones para su tratamiento y, ante una eventual insuficiencia legal, puede válidamente cubrirse con los valores, principios y técnicas de la juridicidad. 
En función de lo expuesto y reiterando lo dicho en trabajos anteriores, considero que pueden establecerse los siguientes caracteres y principios para afrontar las emergencias, dentro del derecho:

1. La emergencia es una situación de crisis extraordinaria, imprevista, grave e intensa que pone en riesgo valores colectivos.

2. Exige por parte del Estado una respuesta pronta y eficaz a través de la "policíade emergencia".

3. La situación "emergente" no puede ser encuadrada en las pautas jurídicas previstas para los casos comunes, o sea, no admite un tratamiento con los instrumentos previstos para la normalidad.

4. Tal juicio de "no admisión" no se refiere sólo a una cuestión de hecho, sino principalmente a un juicio político y valorativo de eficacia.

5. La declaración de emergencia y la invocación de sus causas es un juicio discrecional del poder político que no puede ser sustituido por los jueces yestá exento del control de éstos, salvo casos de arbitrariedad e irrazonabilidad que claramente desnaturalicen derechos personales.

6. La emergencia debe ser declarada por el legislador y no puede hacerlo el Poder Ejecutivo a través de un decreto delegado o de necesidad y urgencia.

7. La declaración de emergencia y las medidas para enfrentarla deben tener claros fines de interés común o general.

8. Debe mediar una adecuada proporción entre los fines y los medios que se empleen.

9. La declaración jurídica de la emergencia y las medidas para conjurarla deben tener carácter temporal o transitorio, apuntando al objetivo final de volver a la normalidad, con restauración de los derechos afectados.

10.La temporalidad también es un juicio librado a la prudencia del legislador, ya que depende del tipo y gravedad de los problemas a enfrentar.

11.El ejercicio de la policía de emergencia por el legislador supone una regulación más intensa de los derechos individuales respecto de tiempos normales, sin que le esté permitido desnaturalizarlos o alterarlos ni, mucho menos, suprimirlos. Tampoco tales derechos quedan suspendidos, a diferencia de lo que acontece con el estado de sitio.

12.En la regulación indicada no es posible seguir políticas discriminatorias, es decir, beneficiar o perjudicar sectores o personas respecto de otros, con la aclaración de que el levantamiento de las restricciones no necesariamente puede tener lugar para todos al mismo tiempo. El seguir una secuencia en la normalización, que vaya contemplando, sucesivamente, distintas situaciones, no significa discriminación o trato desigual.

13.En las regulaciones propias de las situaciones de emergencia gravita el valor de solidaridad social.

14.En síntesis, el tratamiento de las situaciones de emergencia se caracteriza por postergar valores individuales, con compromiso estatal de normalización futura. 


\section{Referencias bibliográficas}

Agamben, G. (2007). Estado de Necesidad. Adriana Hidalgo editora. Buenos Aires.

Agamben, G. (2020). ¿En qué punto estamos? La epidemia como política. Adriana Hidalgo editora. 1a. edición en Argentina y España, Buenos Aires.

Fiorini, B. (1976). Derecho Administrativo, 2da. ed. actualizada, To. I. Buenos Aires. Abeledo-Perrot.

Mata, I., (2009). La competencia como requisito esencial del acto administrativo (desde la visión sistémica y económica), en Ensayos de Derecho Administrativo, Ediciones RAP, Buenos Aires, 193-202.

Nancy, J. (2020). Un Virus Demasiado Humano". Editorial La Cebra. Adrogué.

Petrella, I. (17 de abril de 2021). Mundo tecno ¿Adónde nos está llevando la inteligencia artificial? La Nación. Buenos Aires.

Rodriguez Arana, J. (2013). La buena administración como principio y derecho fundamental en Europa, Revista de Derecho y Ciencias Sociales, Bogotá, Nº 6 . 